\title{
Hernia vesicoescrotal gigante
}

\author{
Gimeno Argente V, Bosquet Sanz M, Alapont Alacreu JM, Luján Marco S, Bango García V, \\ Jiménez Cruz JF.
}

Servicio de Urología. Hospital Universitario La Fe. Valencia.

Actas Urol Esp. 2006;30(10):1046

$\mathrm{V}$ arón de 82 años de edad con antecedentes de tumor vesical superficial recidivante tratado con múltiples resecciones transuretrales, que consultó por escapes de orina relacionados con el esfuerzo de meses de evolución y masa escrotal sugestiva de hernia inguinal. Se realizó cistografía (Fig. 1), que mostró una vejiga de escasa capacidad con una hernia vesicoescrotal derecha de grandes dimensiones. Se procedió a intervención quirúrgica programada, apreciando durante el acto quirúrgico una hernia inguinoescrotal directa "gigante" en el lado derecho, con contenido vesical y lipoma asociado (Fig. 2). Se reparó el defecto mediante hernioplastia inguinal con disec-

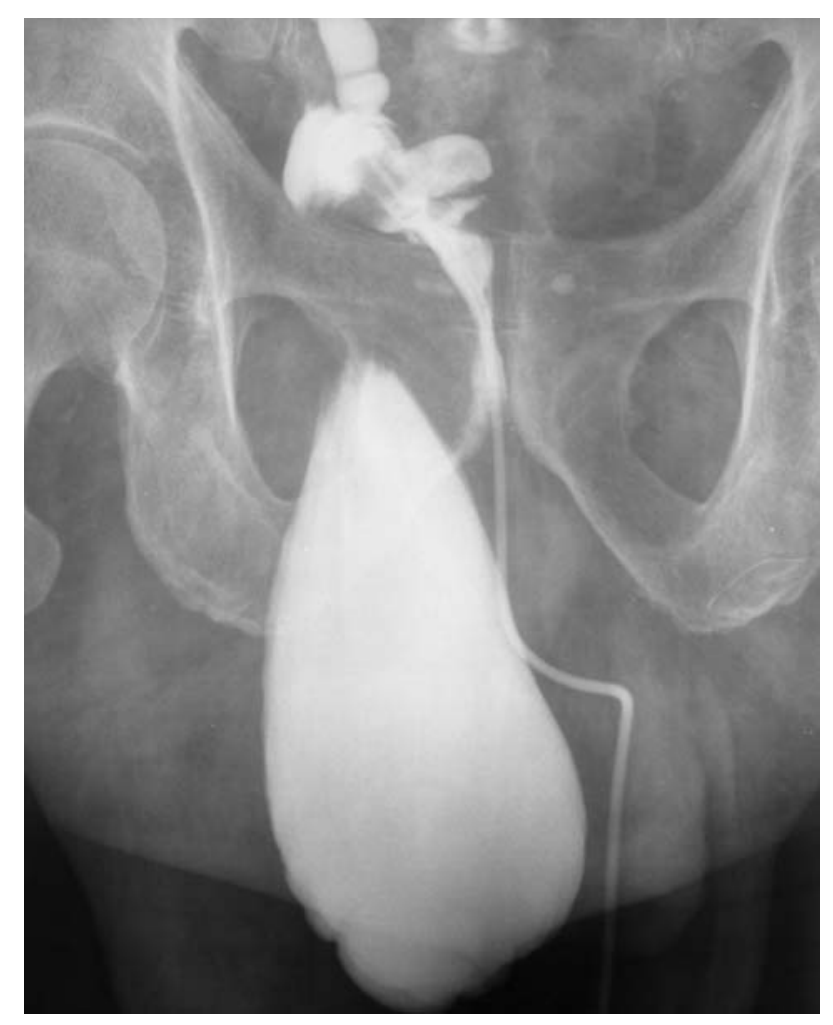

FIGURA 1 ción del cuello herniario y reducción de todo el contenido a pelvis menor. A continuación se efectuó plicatura con malla fijada a tendón conjunto, espina del pubis y ligamento inguinal.

La evolución fue satisfactoria, desapareciendo la incontinencia urinaria.

Dr. V. Gimeno Argente

E-mail: vigiar71@hotmail.com

(Trabajo recibido el 15 de marzo de 2006)



FIGURA 2 